\title{
Angioleiomyoma: a rare diagnosis of a painful subcutaneous nodule in the hand
}

\author{
Sandeep Bhogesha1, Satyaswarup Tripathy', Jerry R. John¹, Debajyoti Chatterjee ${ }^{2}$ \\ ${ }^{1}$ Department of Plastic Surgery, Post graduate Institute of Medical Education and Research, Sector 12, Chandigarh 160012, India. \\ ${ }^{2}$ Department of Pathology, Post graduate Institute of Medical Education and Research, Sector 12, Chandigarh 160012, India.
}

Address for correspondence: Dr. Satyaswarup Tripathy, Department of Plastic Surgery, Post graduate Institute of Medical Education and Research, Sector 12, Chandigarh 160012, India. E-mail: dr.sstripathy@gmail.com

\begin{abstract}
Angioleiomyoma of the hand is a rare differential diagnosis of painful soft tissue nodule in the extremity. It arises from smooth muscle of the blood vessels and the most common symptom is pain. Imaging with magnetic resonance imaging shows characteristic features like a hypodense peripheral capsule with linear or branching internal hyperdensities on T2-weighted images, and post-contrast diffuse homogenous enhancement with a vessel leading up to the lesion. Histopathological examination shows well circumscribed fascicles of mature smooth muscle cells surrounding vascular lumina, lined by normal appearing endothelium without elastic lamina present. These cells stain positive for smooth muscle actin, desmin, vimentin, type IV collagen and S100, but stain negative for HMB-45 and ER. Angioleiomyoma is amenable for surgical resection. We report a case of painful subcutaneous nodule of hand, with radiological and histopathological findings suggestive of angioleiomyoma. We outline the clinical, radiological and histopathological features of this rare diagnosis for painful nodule of extremity.
\end{abstract}

Key words:

Hand; tumor; angioleiomyoma; histopathology; excision; biopsy

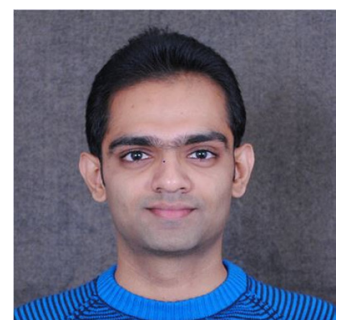

Dr. Sandeep Bhogesha is Senior Resident in Plastic Surgery in PGIMER, Chandigarh, India. His research interests include outcomes of nerve pathologies in the upper limb and craniofacial surgery.

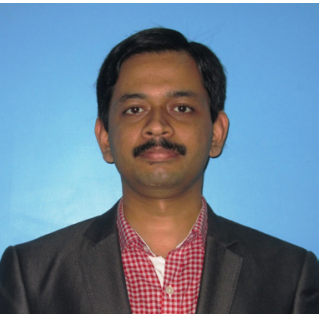

Dr. Jerry R. John is Assistant Professor in Plastic Surgery in PGIMER, Chandigarh, India. He is a reconstructive microsurgeon. His areas of interest include trauma, burn and onco-reconstruction; perforator flaps and outcome research in lower limb trauma.

\begin{tabular}{|l|l|}
\hline \multicolumn{2}{|c|}{ Access this article online } \\
\hline Quick Response Code: & Website: \\
\hline & http://parjournal.net \\
\cline { 2 - 3 } & \\
\cline { 2 - 3 } &
\end{tabular}

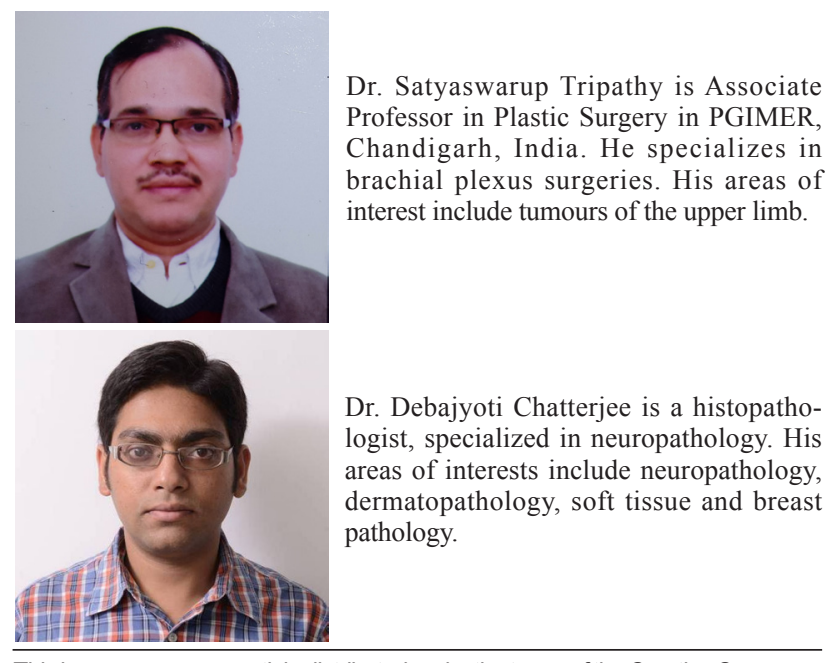

This is an open access article distributed under the terms of the Creative Commons Attribution-NonCommercial-ShareAlike 3.0 License, which allows others to remix tweak and build upon the work non-commercially, as long as the author is credited and the new creations are licensed under the identical terms.

For reprints contact: service@oaepublish.com

How to cite this article: Bhogesha S, Tripathy S, John JR, Chatterjee D. Angioleiomyoma: a rare diagnosis of a painful subcutaneous nodule in the hand. Plast Aesthet Res 2016;3:126-8

Received: 14-08-2015; Accepted: 17-11-2015 


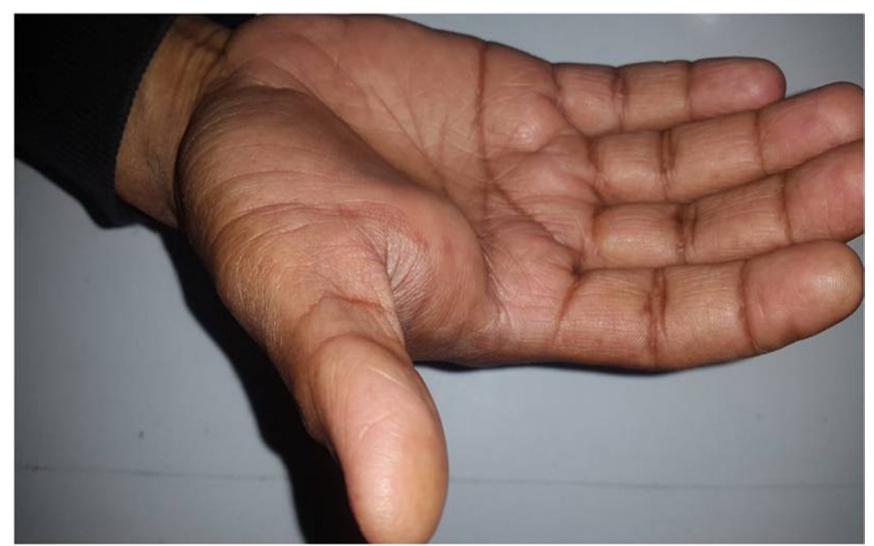

Figure 1: Preoperative picture. Note the bulge over the thenar eminence

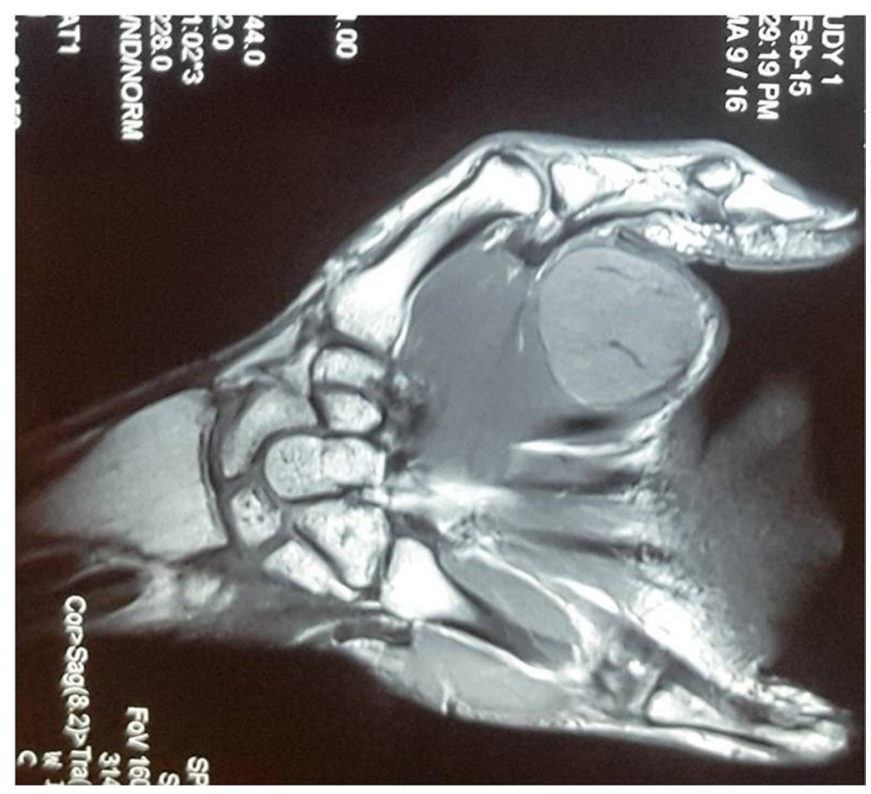

Figure 2: MRI showing well defined lesion in the thenar area. MRI: magnetic resonance imaging

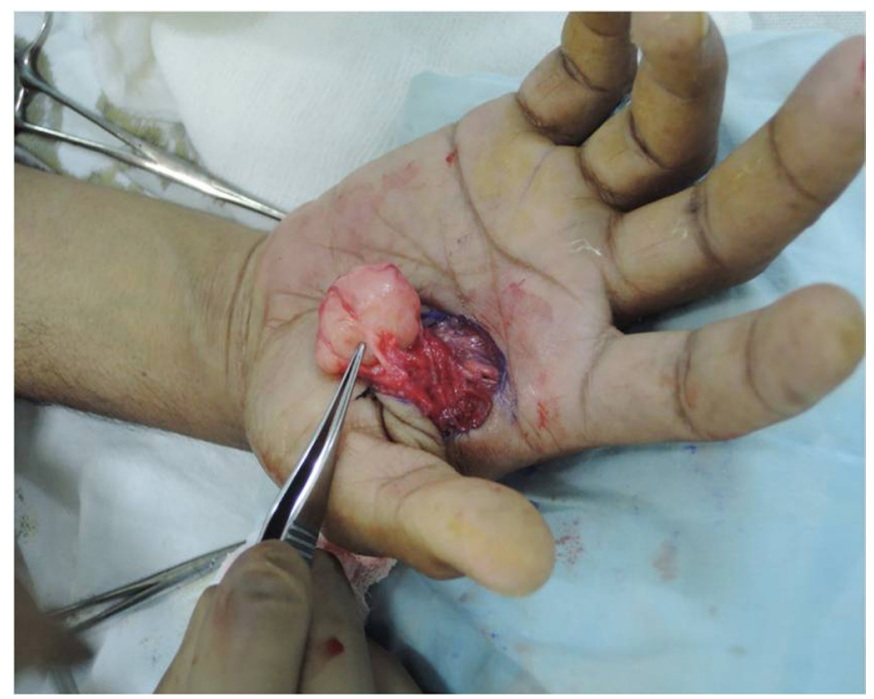

Figure 3: Intraoperative view showing a blood vessel from the palmar arch in close proximity to the tumor

\section{INTRODUCTION}

Angioleiomyoma is a unique form of soft tissue tumor, which arises from the smooth muscle of blood vessels. ${ }^{[1]}$ This tumor can appear in different parts of the body, and the most

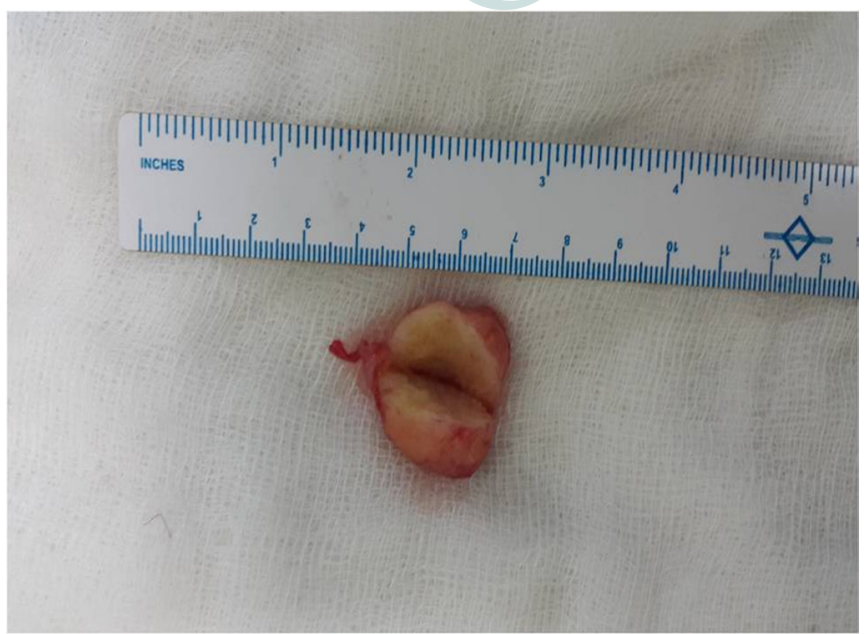

Figure 4: Gross cut section

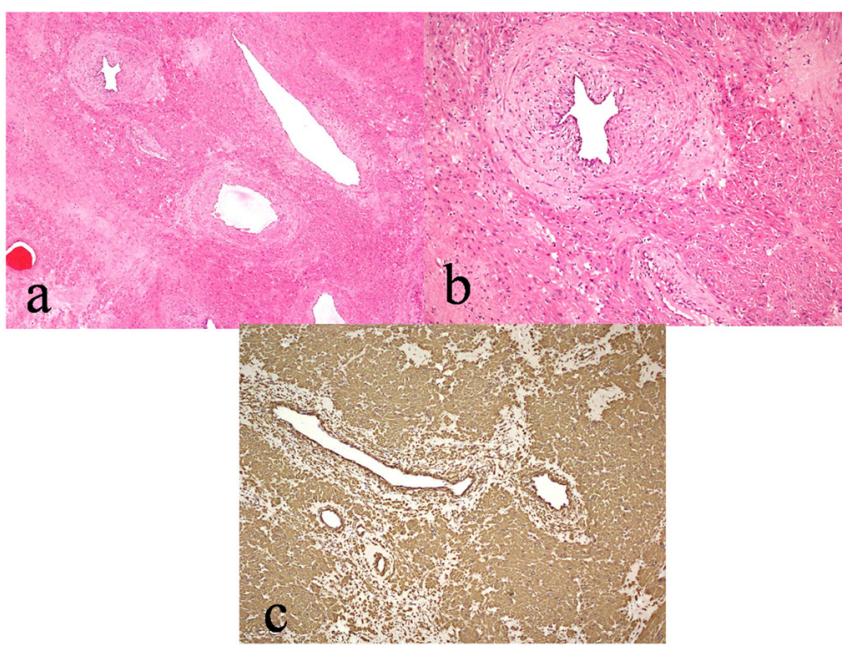

Figure 5: (a) Photomicrographs showing a tumor composed of bundles of smooth muscles with intervening blood vessels $(\mathrm{HE}, \times 100)$; (b) higher magnification showing bland nature of the smooth muscles and intervening thick muscular blood vessel (HE, $\times 200)$; (c) the tumor cells show strong positivity for smooth muscle actin $(\mathrm{IP}, \times 100)$

common presenting complaint is pain. Since this lesion is a rare occurrence and the list of differential diagnoses for painful mobile subcutaneous mass is extensive, a case report and literature review of angioleiomyoma is presented.

\section{CASE REPORT}

A 36-year-old man presented with a 2-year history of a slowgrowing, mildly painful mass in the palmar aspect of the thenar eminence of the right hand. There was no history of trauma. On examination, a $3 \mathrm{~cm} \times 2 \mathrm{~cm}$ firm, mobile mass was palpated on the thenar eminence of the right hand. The lesion did not extend to the underlying bone and tendon. The overlying skin could be easily pinched from the lesion and did not show ulceration or discoloration. Temperature and sensation of the overlying skin was normal. Thus, a clinical diagnosis of soft tissue tumor was made [Figure 1].

Magnetic resonance imaging (MRI) of the hand revealed a well-defined $2.5 \mathrm{~cm} \times 2.8 \mathrm{~cm}$ lesion in the first web space of the right hand infiltrating adjacent musculature. The lesion was heterogeneously hyperdense on T2, and isodense on T1. Prominent feeders were seen from arterial branches of the palmar arch. No 
early draining veins were seen [Figure 2].

Excision of the lesion was performed under brachial block. A single $2 \mathrm{~cm}$ in diameter spherical mass was identified [Figure 3]. The outer surface was smooth and whitish in color. It was well encapsulated [Figure 4]. Histopathology revealed a well-circumscribed tumor, composed of multiple thick-walled blood vessels with thickened smooth muscle coating. The smooth muscles were arranged in form of interlacing fascicles. Neither mitosis nor necrosis was seen. Tumor cells were positive for smooth muscle actin and desmin, but they were negative for $\mathrm{Bcl}-2$ and $\mathrm{CD} 34$. The features were consistent with angioleiomyoma or vascular leiomyoma [Figure 5].

The patient was kept on regular follow-up. Six months following surgery, there are no signs of recurrence.

\section{DISCUSSION}

Angioleiomyomas are rare benign subcutaneous or deep dermal tumors of smooth muscle and vessels. They are also called angiomyomas or vascular leiomyomas. They are common among females in 30-60 years of age.

Angioleiomyomas present as slow growing painful solitary nodules of extremities. ${ }^{[2-5]}$ Other rare sites have also been reported in the literature including the labia majora, nipple, hard palate, ${ }^{[6]}$ pinna, and sella. ${ }^{[7]}$ The most common presenting symptom is pain, found in up to $60 \%$ of cases. ${ }^{[8]}$ This is attributed to stretching of nerves in tumor or capsule, or release of mediators from mast cells.

Differential diagnoses to be considered in cases of painful nodules in extremities are glomus tumor, traumatic neuroma, eccrine spiradenoma and angiolipoma. ${ }^{[1,9]}$ All are treated by surgical excision and they do not reoccur. The gross appearance is firm and spherical nodule that is grayish white to brown in color, and usually $2 \mathrm{~cm}$ or less in diameter.

MRI features characteristic to angiomyomas include a hypodense peripheral capsule with linear or branching internal hyperdensities on T2-weighted images, and postcontrast diffuse homogenous enhancement, with a vessel leading up to the lesion in the majority of cases. These features were also seen in our case.

Histopathological examination showed well-circumscribed fascicles of mature smooth muscle cells surrounding vascular lumina, ${ }^{[10]}$ lined by normal appearing endothelium without elastic lamina. There are subtypes described in literature: (1) solid type-closely compacted smooth muscle bundles; (2) venous type-vessels have thick muscular walls that merge with smooth muscle bundles; and (3) cavernous type-dilated vascular channels with minimal smooth muscle that merges with smooth muscle bundles. The venous type is observed more in males, and in the region of the head and neck. The solid type is more common in women, and in the lower extremities.
They may have foci of cartilaginous or adipose metaplasia. Rarely, they might have calcification. ${ }^{[11]}$ Hemorrhage, necrosis, mitotic activity, vasculitis or fibromuscular dysplasia are not encountered.

Morphologically they have moderate or sparse cellularity. They are composed of bundles of smooth muscles arranged in varying size fascicles admixed with varying amount of collagen with intervening vascular structures. Occasional macrophages, fat cells and ganglion-like cells are seen. Angiomyolipoma is a histological differential diagnosis. This lesion usually contains adipose tissue in addition to smooth muscle and vascular components. Angioleiomyoma cells stain positive for smooth muscle markers like alpha smooth muscle actin, desmin, myosin, trichrome, HHF-35, calponin and h-caldesmon. These cells are also positive for vimentin, type IV collagen and variably for S100. They stain negative for HMB-45 and estrogen receptor.

To conclude, angioleiomyoma of the hand is a rare differential diagnosis of a painful subcutaneous nodule in the extremities and has to be kept in mind during such clinical presentation.

\section{Financial support and sponsorship}

Nil.

\section{Conflicts of interest}

There are no conflicts of interest.

\section{REFERENCES}

I. Ohtsuka H.Angioleiomyoma of the pulp.J Plast Surg Hand Surg 2014;48:2856.

2. Mok JC, Fan KY, Lui TH. A huge angioleiomyoma of the finger. Hand Surg 2015;20:310-2.

3. Nishio J, Aoki M, Tanaka Y, Iwasaki H, Naito M. Painless angioleiomyoma of the first web space of the hand. In Vivo 2013;27:519-22.

4. Ogura K, Goto T, Nemoto T. Painless giant angioleiomyoma in the subfascia of the lower leg.J Foot Ankle Surg 2012;51:99-102.

5. Raval A, Schulder M, Al-Atassi S. Neurosurgical management of a painful subcutaneous nodule of the knee: angioleiomyoma. Neurosurgery 2014;75:EI90-4

6. Eley KA, Alroyayamina S, Golding SJ, Tiam RN, Watt-Smith SR. Angioleiomyoma of the hard palate: report of a case and review of the literature and magnetic resonance imaging findings of this rare entity. Oral Surg Oral Med Oral Pathol Oral Radiol 2012; I 14: e45-9.

7. Xu Y, Jing Y, Ma S, Ma F,Wang Y, Ma W, Li Q. Primary angioleiomyoma in the sellar region: a case report and literature review. Clin Neuropathol 2010; 29:21-5.

8. Hachisuga T, Hashimoto H, Enjoji M. Angioleiomyoma. A clinicopathologic reappraisal of 562 cases. Cancer 1984 I;54:126-30.

9. Lee HH, Park SH, Choi HY, Park HK. Eccrine spiradenoma arising in the breast misdiagnosed as an epidermal inclusion cyst. Korean J Radiol 201 I; 12:256-60.

10. Shafi M, Hattori Y, Doi K. Angioleiomyoma of distal ulnar artery of the hand. Hand (NY) 2010;5:82-5.

II. Onishi M, Takahashi K, Watabe D, Onodera H, Akasaka T. A case of angioleiomyoma with epithelioid granuloma. Case Rep Dermatol 201I; $3: 170-4$. 